\title{
Entrepreneurship
}

Jul a Dez $2018-$ v.2 - n.2

ISSN: 2595-4318

This article is also available online at:

\section{Atividade de auditoria contábil: um enfoque teórico de sua aplicação em empresas}

A Auditoria tem por finalidade examinar cientificamente, de forma sistemática, livros, contas, comprovantes e outros registros financeiros de uma empresa, com o propósito de determinar a integridade do sistema de controle interno contábil das demonstrações financeiras. É um ramo da contabilidade e importante instrumento na prevenção e combate a erros e fraudes nas organizações, com a função de reduzir e, até mesmo, dirimir a prática desses delitos. Atualmente, podese observar que a Auditoria, cada vez mais, centra-se na orientação para tomada de decisão que vise à melhor eficiência e eficácia das empresas, nos procedimentos adotados em lançamentos de fatos contábeis, do que para penalizar o erro praticado por elas por falta de conhecimento. Preocupa-se, também, com a manutenção dos sistemas financeiros para melhor adequá-los às normas da Lei em vigor, indicando sugestões para eventuais desvios de incompatibilidade com a legislação. A presente monografia tem como objetivo evidenciar os principais procedimentos da Auditoria em empresas comerciais, confirmando recomendações e sugestões mais adequadas nesse processo. Com uma visão mais apurada do trabalho de Auditoria, destaca-se a importância do controle minucioso realizado por ela, constituindo-se em instrumento de amplo controle para os empresários, auxiliando na captação de informações confiáveis de sua situação patrimonial e financeira. Para a realização do presente estudo foram desenvolvidas leituras e interpretações em material disponível eletronicamente, além de pesquisas bibliográficas. Como resultado, pretende-se ampliar a discussão sobre o tema, esclarecendo dúvidas e ampliando o conhecimento, com a intenção de atualizar-se para ganhar espaço dentro de um mercado de trabalho cada vez mais competitivo.

Palavras-chave: Auditoria; Procedimentos; Empresas Comerciais; Demonstrações Financeiras.

\section{Accounting audit activity: a theoretical approach to its application in companies}

The audit aims to examine scientifically, systematically, books, accounts, vouchers and other financial records of an enterprise for the purpose of determining the integrity of the system of internal accounting control of the financial statements. It is a branch of accounting and important tool in preventing and combating fraud and errors in organizations, with the task of reducing and even the outcome of such offenses. Currently, one can observe that the Audit Committee increasingly focuses on guidance for decision-making that aims to better efficiency and effectiveness of enterprises in the procedures adopted in the release of accounting facts, rather than to penalize the error committed by same lack of knowledge. She worries, too, with the maintenance of financial systems to better tailor them to the standards of the law in force, indicating suggestions for possible deviations of incompatibility with the law. This monograph aims to highlight the main auditing procedures in commercial enterprises, confirming the most appropriate recommendations and suggestions in this process. With a more accurate picture of the work of audit, emphasizes the importance of careful controls performed by the same, being in full control tool for entrepreneurs, assisting in the collection of reliable information of your assets and financial situation. To perform this study were developed readings and interpretations of material available electronically, and literature searches. As a result, we intend to broaden the discussion on the topic, clarifying doubts and enhancing the knowledge, intended to upgrade itself to save space within a labor market increasingly competitive.

Keywords: Audit; Procedures; Business Enterprises; Financial Statements.

\section{Topic: Finanças Empresariais}

Reviewed anonymously in the process of blind peer.
Received: $12 / 01 / 2018$

Approved: 20/04/2018
Crislaine Florence Cruz (iD)

Faculdade Uninassau Aracaju, Brasil

http://orcid.org/0000-0002-1024-6579

crislaineflorencio21@gmail.com

Alvani Bomfim de Sousa Júnior (DD

Faculdade Uninassau Aracaju, Brasil

http://lattes.cnpq.br/6358502728889050

http://orcid.org/0000-0002-8714-4175

alvanijunior@yahoo.com.br

\section{Referencing this:}

CRUZ, C. F.; SOUSA JÚNIOR, A. B.. Atividade de auditoria contábil: um enfoque teórico de sua aplicação em empresas. Entrepreneurship, v.2, n.2, p.1-16, 2018. DOI: http://doi.org/10.6008/CBPC25954318.2018.002.0001

DOI: 10.6008/CBPC2595-4318.2018.002.0001 


\section{INTRODUÇÃO}

A Auditoria é uma ramificação da Contabilidade, da qual a sociedade exige cada vez mais colaboração para dirimir atos ilegais que possivelmente aconteçam nas empresas, além de ser utilizada na prevenção contra eventuais irregularidades.

O trabalho de Auditoria, desde que bem elaborado, gera confiabilidade perante a opinião pública em relação às demonstrações e relatórios emitidos pela Contabilidade. Para Santos et al. (2006), "tanto usuários internos como externos necessitam de informações fidedignas, exatas, apresentadas honestamente e isentas de distorções".

Na contemporaneidade, a Auditoria passa a ser vista como um instrumento de controle administrativo que mede e avalia a eficácia de outros controles, estendendo-se, necessariamente, pelos diversos segmentos de uma empresa, assim como aos fatores externos que, de alguma forma, influenciam os dados da contabilidade, tendo em vista que sua principal finalidade é avaliar as informações contábeis, com o objetivo de verificar se as mesmas são confiáveis, adequadas, totais e seguras.

A análise criteriosa dos controles internos e dos procedimentos de trabalho, aliada a sugestões de melhoria, aumenta sobremaneira o desempenho operacional, bem como a qualidade técnica dos serviços ou mesmo da produção. Nesse sentido, a utilização dos recursos da Auditoria permite que empresários e dirigentes adquiram o entendimento do grau de risco de suas atividades, de maneira a maximizar a eficiência e melhorar a qualidade do trabalho.

Dentro de uma visão pragmática, a Auditoria é fundamentalmente crítica, voltando-se para o levantamento, estudo e avaliação sistemática das transações, procedimentos, operações, rotinas e demonstrações financeiras, de modo a assegurar a correta utilização dos recursos da empresa, tanto de natureza financeira, quanto econômica e/ou humana.

Considerando que a inexistência de um controle interno torna favorável a ocorrência de irregularidades, a Auditoria, utilizando-se da Contabilidade como ferramenta para coleta de informações, assume grande importância, haja vista que possibilita esclarecimentos de fatos que devem coincidir com a realidade da empresa, evitando, assim, crimes.

O interesse pelo tema ocorre pelo fato de que a Auditoria, ao longo do tempo, vem ganhando notoriedade como instrumento de especialização contábil, mas, principalmente, pelo fato de que se destina a ser usada para confirmação da própria contabilidade. A veracidade das informações, o correto cumprimento das metas, a aplicação do capital investido de forma lícita e o retorno do investimento são algumas das preocupações que fazem com que essa ferramenta adquira excepcional desenvolvimento, diante de sua característica tipicamente controladora.

Considerando-se que a auditoria não se limita apenas em verificações de fatos passados, observa-se, ainda, que o seu conceito atual é dinâmico, atribuindo-lhe outras importantes funções que abrangem todo o organismo da empresa e da sua administração, tais como: interpretação, previsão de fatos, exame e crítica, como consequência das suas interpretações. 
Dessa maneira, ao assumir importância como elemento informativo e de apoio aos administradores em geral, a Auditoria torna-se de grande utilidade para a determinação da real situação de uma empresa, em termos de seus direitos, obrigações e resultados das operações realizadas no período examinado.

Este trabalho que tem como tema: Atividade de Auditoria Contábil, procura fazer uma análise de sua aplicação em empresas comerciais brasileiras, investigando o modo como ocorre esse processo na contemporaneidade. $\mathrm{E}$, diante do objeto de estudo, tal como aqui delimitado, tem-se, como problema de pesquisa, a seguinte formulação: Na atualidade, como a Auditoria pode se constituir uma ferramenta eficaz de controle para as empresas comerciais, de maneira a propiciar-Ihes confiabilidade e eficiência?

A presente pesquisa tem como objetivo geral discorrer sobre a atividade de Auditoria Contábil, enfatizando os procedimentos que são aplicados pelas empresas. Para isso, determinam-se como objetivos específicos: caracterizar a evolução histórica da Auditoria até seu contexto atual nas organizações brasileiras; demonstrar a importância da Auditoria Contábil e Identificar os métodos e rotinas praticados no processo de Auditoria Contábil.

A elaboração do presente trabalho, portanto, justifica-se pela necessidade de se estudar os procedimentos adotados pela Auditoria Contábil no âmbito das entidades comerciais, em virtude da dinâmica de mercado em sistema de livre concorrência, sobretudo dentro do mundo globalizado, no que seja: aumento do nível de exigência dos clientes, recursos limitados e maior necessidade de transparência no cumprimento de sua responsabilidade empresarial.

A presente monografia se enquadra no formato da pesquisa bibliográfica, pois, de acordo com Oliveira (2002), "a pesquisa bibliográfica tem por finalidade conhecer as diferentes formas de contribuição científica que se realizaram sobre determinado assunto ou fenômeno".

\section{METODOLOGIA}

O presente trabalho se enquadra no formato da pesquisa bibliográfica, pois, de acordo com Oliveira (2002), "a pesquisa bibliográfica tem por finalidade conhecer as diferentes formas de contribuição científica que se realizaram sobre determinado assunto ou fenômeno". Sendo assim, o estudo está pautado na abordagem qualitativa, trazendo uma análise acerca da atividade de Auditoria, utilizando-se, para tanto, de referências com fundamentos teóricos e específicos localizados em artigos, boletins informativos das áreas de Ciências Contábeis, artigos científicos publicados em sites acadêmicos e relacionados à temática. $\mathrm{A}$ pesquisa buscou apresentar obedecendo à seguinte estrutura: a introdução, têm-se a explicação do tema e o problema do estudo, definem-se os objetivos do trabalho e as razões de sua elaboração, além de se fazer uma breve revisão da literatura pertinente a Auditoria Contábil; na segunda parte a revisão teórica, abordase a Perspectiva Histórica da Contabilidade que fornece um breve relato da concepção dessa atividade desde os primórdios da civilização. Nessa trajetória, constata-se a origem e Evolução da Auditoria, como ramo da Contabilidade, buscando-se, nos registros de Crepaldi (2010), o processo de sua institucionalização no Brasil; na terceira parte trata dos Aspectos Básicos da Auditoria, enfocando os principais e procedimentos adotados pelos auditores no exercício de suas atribuições. Autores como ludícibus (2000), Franco et al. (2001), Oliveira 
(2002), dentre outros, contribuem com os conceitos teóricos sobre os temas relacionados com o assunto da revisão bibliográfica; e na quarta parte apresenta as peculiaridades das Sociedades Comerciais, as quais diferem das demais, buscando identificar os procedimentos de auditoria mais adequados para serem utilizados no âmbito dessas empresas. Por fim, apresentam-se as conclusões do estudo realizado, além das referências que o fundamentam.

\section{REVISÃO TEÓRICA}

\section{Perspectiva histórica da contabilidade e origem da auditoria}

Afirmando ser o homem naturalmente ambicioso, ludícibus (2000) cita que a necessidade do mesmo em contabilizar seus recursos advém desde o início da civilização. Alguns teóricos preferem dizer que a necessidade de contabilizar, ou seja, a Contabilidade existe, pelo menos desde 4000 anos antes de Cristo, quando o homem, havendo um pequeno monte de pedras ao seu lado, separou uma pedra para cada cabeça de ovelha, executando assim o que o contabilista chamaria hoje de inventário.

A Contabilidade surgiu como uma parte do conhecimento humano, em função da necessidade básica do homem de contar seus rebanhos, produtos de sua pesca ou caça, cujo objetivo seria garantir o resultado positivo da equação entre necessidade de recursos e a disponibilidade para subsistência (CREPALDI, 2010).

Pela análise desses autores, torna-se possível verificar que a Contabilidade apareceu, ainda que de forma rudimentar, como um instrumento de medição e avaliação de bens, ligando-se às primeiras necessidades humanas de proteção à posse de suas riquezas individuais.

Assim, desde o período primitivo a contabilidade se desenvolveu, sempre em função das modificações das relações econômicas ocorridas no mundo, marcadas por períodos assim definidos por Sá (1995 citado por ALBERTON, 2002): Idade Antiga da Contabilidade - compreende a escrituração dos fatos patrimoniais pelos sumérios, babilônios, egípcios, assírios, cretenses, gregos, romanos e outras civilizações, no período de 6000 anos antes de Cristo a 1202 depois de Cristo; Idade Média da Contabilidade - foi marcada pelo aparecimento do método do registro contábil pelas partidas dobradas, no período de 1202 a 1494; Idade Moderna da Contabilidade - marcada pela divulgação das primeiras obras sobre a técnica dos registros patrimoniais, com destaque para a obra Tractatus, de Luca Pacioli em 1494, e pelos estudos científicos de Francesco Villa, no ano de 1840; Idade Científica ou Contemporânea da Contabilidade - marcada pela sistematização do conhecimento contábil, no período de 1840 até os dias atuais.

Em cada período, observa-se que a trajetória evolutiva da Contabilidade é dinâmica, caracterizada pela busca por formas mais eficientes de processar seus registros, procurando quebrar os paradigmas proporcionados nas diferentes idades de sua história.

De acordo com Attie (1998 citado por ALBERTON, 2002), a Escola Italiana iniciou o processo de desenvolvimento da teoria da contabilidade entre 1840 até 1920, quando, a partir desse período, passou a predominar a Escola Anglo-Americana de Contabilidade, desenvolvendo a Contabilidade de Custos, Gerencial, Análise de Balanços, Auditoria e outras ramificações técnicas. 
Além dessas escolas, Schmidt (2000) menciona outras, como a Escola Alemã, no final do século XIX e início do século $\mathrm{XX}$, que teve como principal contribuição o desenvolvimento doutrinário da Contabilidade; e, a Escola Francesa ou Neocontista, também no final do século XIX, que estabeleceu procedimentos para a elaboração dos balanços das empresas. 0 autor ressalta que, em 1880, foi realizado na França um congresso de contadores, no qual houve um consenso sobre a padronização dos balanços patrimoniais.

Portanto, a partir de 1840, a contabilidade passou a fazer parte dos princípios científicos, acompanhando a evolução do sistema empresarial e das economias de mercado. O conceito de sociedade foi sendo aprimorado e tornou-se possível distinguir a entidade empresarial e os seus proprietários, conduzindo ao entendimento de que:

Contabilidade é a ciência- ou, segundo alguns, a técnica- destinada a estudar e controlar o patrimônio das entidades do ponto de vista econômico e financeiro, observando seus aspectos quantitativos e qualitativos e às variações por ele sofridas, com o objetivo de fornecer informações sobre o estado patrimonial e suas variações em determinado período (FRANCO et al., 2001).

Seguindo a orientação dos doutrinadores, a Contabilidade pode ser reconhecida como arte, como técnica ou como ciência, caracterizando-se, sobretudo, por se constituir no conjunto ordenado de conhecimentos com objeto e finalidade definidos, o que permite enquadrá-la no elenco das espécies do saber humano.

$\mathrm{Na}$ acepção ampla do conceito de ciência, enquadra-se como uma das ciências econômicas e sociais, cujo objeto de estudo é, pois, o patrimônio administrável à disposição das entidades econômicoadministrativas, sobre o qual fornece as informações necessárias à avaliação da riqueza patrimonial e dos resultados produzidos por sua gestão. Para atingir sua finalidade, utiliza-se, de acordo com Marra e Franco (2001), das seguintes técnicas contábeis:

Escrituração - registro, em livros próprios (Diário, Razão, Caixa e Contas Correntes), de todos os fatos administrativos que ocorrem no dia a dia das empresas;

Demonstrações - quadros técnicos que apresentam dados extraídos dos registros contábeis da empresa, sendo o Balanço Patrimonial e a Demonstração do Resultado do Exercício, as demonstrações financeiras mais conhecidas;

Auditoria - verificação da exatidão dos dados contidos nas demonstrações financeiras, através do exame minucioso dos registros contábeis e dos documentos que deram origem a eles;

Análise de Balanços - exame e interpretação dos dados contidos nas demonstrações financeiras, com o fim de transformar esses dados em informações úteis aos diversos usuários da Contabilidade.

Dentre tais técnicas, o surgimento da Auditoria, em essência, está fortemente atrelado a fatos marcantes da história da Contabilidade, como um marco de aprimoramento do sistema contábil e decorrente de sua evolução, frente ao desenvolvimento econômico dos países. Portanto, para se conhecê-la, tal como é vista atualmente, deve-se analisar o seu processo histórico, a sua origem e o motivo pelo qual ela se tornou uma atividade necessária aos bons andamentos dos diversos negócios a que se aplicava. 


\section{Evolução da Auditoria}

Para Crepaldi (2010), Auditoria é "o levantamento, estudo e avaliação sistemática das transações, procedimentos, operações, rotinas e das demonstrações financeiras de uma entidade". Sua origem, embora discutida de forma rigorosa pelos especialistas, é relacionada, por Boynton, Johnson e Kell (2002, p. 36), com o início das atividades econômicas desenvolvidas pelo homem, afirmando os autores que a:

Auditoria começa em época tão remota quanto à contabilidade. Sempre que o avanço da civilização tinha implicado que a propriedade de um homem fosse confiada, em maior ou menor extensão, a outra, a desabilidade da necessidade de verificação da fidelidade do último, tornou-se clara.

Nessa perspectiva, documentos históricos afirmam que os imperadores romanos nomeavam altos funcionários para supervisionar todas as operações financeiras de seus administradores provinciais a fim de que lhes fossem prestadas contas das mesmas, daí advindo a expressão Auditoria, originada do latim audire, que significa ouvir, segundo Crepaldi (2010). Encontra-se, também, no século II, na França, que os barões realizavam a leitura pública das contas de seus domínios, na presença dos funcionários designados pela Coroa.

Já o cargo de auditor foi criado na Inglaterra, no final do século XIII, durante o poder do rei Eduardo, que o mencionava sempre que se referia ao exame das contas, inclusive daquelas relativas ao testamento de sua falecida esposa. Sob a alegação de que as contas não estivessem corretas iria punir seus responsáveis, o próprio rei, mediante ato do Parlamento, outorgava direito aos barões para nomear seus representantes oficiais os quais recebiam a designação de auditores, cuja aprovação era certificada em documentos que se constituíram nos primeiros relatórios de Auditoria, denominados de Probatur Sobre as Contas.

A Inglaterra, empregando o mercantilismo, dominando os mares e controlando o comércio; mantendo grandes companhias comerciais; e, instituindo impostos sobre o lucro das empresas para desenvolver a riqueza nacional e firmar-se como uma das grandes potências mundiais, em fins do século XVII, foi o país que mais desenvolveu a Auditoria, mas somente, séculos depois, em seguida a crise do ano de 1929, que essa efetivamente começou a prosperar.

Decorrente da necessidade de confirmação dos registros contábeis, em virtude do aparecimento das grandes empresas e da taxação do imposto de renda, baseado nos resultados apurados em balanço, a Auditoria evoluiu paralelamente ao desenvolvimento econômico. Nesse contexto, as grandes empresas, formadas por capitais de muitas pessoas, buscavam na confirmação dos registros contábeis a proteção ao seu patrimônio.

Muito embora, praticada em contas públicas da Inglaterra desde 1314, a Auditoria somente apareceu como prática sistematizada no século XIX, conforme se depreende do fato de que a partir da segunda metade desse século é que começaram a surgir as primeiras associações de Contadores Públicos, profissionais que exercem as funções de auditor, de acordo com o relato de Franco et al. (2001).

Em meados dos anos 30, foi criado o famoso Comitê May, conhecido como um grupo de trabalho formado para determinar regras para as empresas que tivessem suas ações cotadas em bolsa de valores, 
tornando obrigatória a Auditoria Contábil Independente, nas demonstrações financeiras dessas organizações (CREPALDI, 2010).

Esclarece ainda Crepaldi (2010), que os auditores independentes, para exercerem suas atividades, precisavam utilizar informações e documentos que permitissem o profundo conhecimento e análises das diversas transações financeiras. Para auxiliá-los, eram indicados alguns funcionários da própria empresa, que por sua vez, com o decorrer do tempo, aprendiam e dominavam as técnicas de Auditoria, utilizando-as em trabalhos solicitados pela própria administração. Essas empresas, ao perceberem a possibilidade de diminuir seus custos com Auditoria Externa, aproveitavam mais esses funcionários, implantando um serviço de conferência e revisão interna dos trabalhos contábeis, de forma continuada e permanente, a preço menor.

Os auditores externos também lucraram com isso, pois puderam se dedicar exclusivamente ao seu maior objetivo de examinar a situação econômico-financeira das empresas contratantes. Nos Estados Unidos da América, por exemplo, as grandes empresas de transporte ferroviário criaram unidades fiscais chamadas Travelling Auditors (i. e. Auditores Viajantes), que tinham a função de visitar as estações rodoviárias e assegurar que todo produto da venda de passagens e de fretes de carga estavam sendo arrecadados e contabilizados corretamente. Porém, apenas após a fundação do The Institute of Internal Auditors, ou seja, Instituto de Auditores Internos, em Nova York, é que a auditoria interna passou a ser vista de forma diferente. De um corpo de funcionários de linha, costumeiramente subordinados a contabilidade, aos poucos passou a ter um enfoque de controle administrativo, com a finalidade de avaliar a eficácia e a efetividade dos controles internos (CREPALDI, 2010). Logo, o seu campo de ação funcional estendeu-se para todas as áreas da empresa e para manter sua independência, passou a subordinar-se diretamente à alta administração da empresa.

Nos tempos modernos, com a formação de grandes empresas (sociedades abertas), a informação contábil, cuja exatidão dos registros e das demonstrações é confirmada pela Auditoria, passou a ser de interesse de grupos cada vez mais amplos de indivíduos, que incluem não somente acionistas, mas também fornecedores, financiadores, banqueiros, poderes públicos (arrecadadores de impostos) e até empregados que participam do lucro ou dos resultados das empresas. De forma indireta, mesmo a sociedade em geral é interessada na informação contábil, haja vista que a vitalidade das empresas é assunto de relevante interesse social (FRANCO, 2006).

\section{Institucionalização da auditoria no Brasil}

No Brasil, a Auditoria surgiu na época colonial, quando o juiz era a pessoa de confiança do rei, designado pela Coroa portuguesa para conferir o recolhimento dos tributos ao tesouro, no sentido de reprimir e punir fraudes. Posteriormente, no decurso do sistema capitalista, a expansão comercial e a forte concorrência despertaram nas empresas, antes familiares, a necessidades de aumentar suas instalações, investir em tecnologia e aperfeiçoar os controles e procedimentos internos, como por exemplo, a redução de custos, com a intenção de tornar seus produtos mais competitivos no mercado. Para a consecução desses objetivos, tornou-se necessário atrair recursos de terceiros, por meio de empréstimos em longo prazo e abertura do capital social a novos acionistas (CREPALDI, 2010). 
Os investidores precisavam obter informativos sobre a situação financeira e patrimonial, a solvência e a gestão dos recursos da empresa para avaliar a segurança, o grau de liquidez e a rentabilidade. Assim, as demonstrações contábeis tornaram-se os informativos mais importantes e, para maior segurança, os investidores passaram a exigir que as demonstrações fossem examinadas por profissionais independentes e de capacidade técnica reconhecida, a exemplo do que já era realizado nos Estados Unidos da América, na Inglaterra e em outros países desenvolvidos, conforme Correia (2002).

No ano de 1931, através do Decreto no 20.158, a profissão de guardador de livros passou a ser regulamentada, no que se incluía a função de auditor. E, no ano de 1945, por ocasião da lei nº' 7.988 , foi criado o curso de Ciências Contábeis, de nível superior, e de Técnico, de nível médio, tomando a Auditoria uma prerrogativa daquele profissional. Até então, os trabalhos de Auditoria, no Brasil, eram escassos e necessários apenas para o controle administrativo e à formulação de pareceres sobre balanços, ainda como atos formais (CREPALDI, 2010).

Ao final da segunda guerra mundial, os escritórios estrangeiros, acompanhando as instalações de empresas no país, convenceram o empresariado nacional sobre a importância do trabalho de auditoria, e no ano de 1976, com o advento da Lei no 6.404, o parecer do auditor independente nas demonstrações contábeis das companhias abertas tornou-se obrigatório e impulsionou a auditoria brasileira (CREPALDI, 2010).

A evolução da Auditoria no Brasil está primariamente relacionada com a instalação de empresas internacionais de auditoria independente, uma vez que os investimentos também internacionais foram aqui implantados e, compulsoriamente, tiveram de ter suas demonstrações financeiras auditadas. Segundo Correia (2002, p. 21), as principais influências que possibilitaram o desenvolvimento da Auditoria no país foram:
a) filiais e subsidiárias de firmas estrangeiras;
b) financiamento de empresas brasileiras através de entidades internacionais;
c) crescimento das empresas brasileiras e necessidade de descentralização diversificação de suas atividades econômicas;
d) evolução do mercado de capitais;
e) criação de normas de auditoria promulgadas pelo Banco Central do Brasil, em 1972;
f) criação da Comissão de Valores Mobiliários e da Lei das Sociedades Anônimas, em 1976.

A Lei das Sociedades Anônimas determinou que as companhias abertas, além de observarem as normas expedidas pela Comissão de Valores Mobiliários, sejam obrigatoriamente auditadas por auditores independentes registrados na mesma comissão (CREPALDI, 2010).

Em essência, a causa da evolução da Auditoria, que é decorrente da evolução da contabilidade, está ligada ao desenvolvimento econômico dos países, na síntese do crescimento das empresas e da expansão das atividades produtoras, que geram crescente complexidade na administração dos negócios e de práticas financeiras como uma força motriz para o desenvolvimento da economia de mercado.

A veracidade das informações, o correto cumprimento das metas, a aplicação do capital investido de forma lícita e o retorno do investimento foram algumas das preocupações que exigiram a opinião de alguém não 
ligado aos negócios, que confirmasse a qualidade e precisão das informações prestadas, dando, dessa forma, o ensejo ao aparecimento do auditor. Embora cronologicamente haja indícios da existência da profissão de auditor desde o século XIV, essa é, em verdade, uma função nova que vem experimentando excepcional desenvolvimento com diferentes graus de especialização.

\section{Aspectos básicos do trabalho de auditoria}

O objetivo fundamental dos trabalhos de Auditoria consiste em verificar se as demonstrações financeiras representam, adequadamente, a posição patrimonial e financeira da instituição auditada, em uma determinada data. Os resultados das operações, as mutações do patrimônio líquido e as origens e aplicações de recursos para os períodos semestrais ou anuais correspondentes, são analisados de acordo com os princípios de contabilidade geralmente aceitos (CFC, 2003).

Os exames devem ser efetuados de acordo com normas específicas, na extensão julgada necessária às circunstâncias, e determinadas em função dos procedimentos de controle interno da instituição, bem como da relevância de suas contas.

\section{Procedimentos de Auditoria}

Os serviços de auditoria são normalmente solicitados pela administração da empresa, pelo conselho de administração, pela diretoria executiva ou pelo conselho fiscal, não havendo compulsoriamente a obrigação de todas as empresas serem auditadas, exceto aquelas que por determinação legal, estatutária ou por força de contratos ou de empréstimos sejam compelidas a fazê-lo (ATTIE, 1998). Para que a auditoria se cumpra, o autor identifica que existem etapas a serem vencidas, as quais podem ser assim resumidas:

Etapa inicial de auditoria: Solicitação dos serviços de auditoria por empresa interessada; Dimensionamento dos trabalhos de auditoria; Carta-proposta dos serviços de auditoria.

Etapa de execução do trabalho: Estudo e avaliação dos sistemas de controles internos; Testes de procedimentos de controles internos; Seleção e programa de trabalho da auditoria; Aplicação dos procedimentos de auditoria; Evidenciação dos exames efetuados.

Etapa de conclusão da auditoria: Avaliação das evidências obtidas; Emissão do parecer de auditoria; Elaboração dos relatórios de auditoria.

No processo de Auditoria, necessário se faz seguir um roteiro determinado com o objetivo de reunir subsídios e informações em extensão e profundidade adequadas. Segundo Almeida (2003) "os procedimentos de auditoria representam um conjunto de técnicas que o auditor utiliza para colher as evidências sobre as informações das demonstrações financeiras". Na conceituação trazida pela Norma Brasileira de Contabilidade (NBC T 11), de 17 de dezembro de 1997, em seu item 11.1.2.1, consta que:

Os procedimentos de auditoria são o conjunto de técnicas que permitem ao auditor obter evidências ou provas suficientes e adequadas para fundamentar sua opinião sobre as demonstrações contábeis auditadas, abrangendo testes de observância e testes substantivos (CFC, 2003). 
Ao planejar e programar a Auditoria, o auditor considera dez procedimentos que, de acordo com Boynton et al. (2002), são eles: procedimentos de revisão analítica; inspeção; confirmação; questionamento; contagem; rastreamento; vouching; observação; repetição; e, técnicas de auditoria computadorizada.

\section{Elementos Básicos do Parecer de Auditoria}

Após a realização de todo o trabalho de campo, no qual reuniu provas e evidências sobre as demonstrações financeiras, o auditor determina seu entendimento sobre a representatividade e o conjunto das mesmas, através de um parecer. A emissão do parecer reflete o entendimento do auditor acerca dos dados em exame, dentro de uma forma padrão e resumida que permite, aos leitores, em geral, uma noção exata dos trabalhos realizados e o que concluiu. Na definição de Attie (1998), "o parecer de auditoria é o instrumento pelo qual o auditor expressa sua opinião, em obediência às normas de auditoria". De acordo com o Instituto Brasileiro de Contabilidade (IBRACON, s. d.), o parecer emitido pelo auditor compõe-se, basicamente, dos três parágrafos seguintes:

10 Parágrafo: determina e referência o propósito do trabalho do auditor e a responsabilidade por ele assumida.

20 Parágrafo: determina a abrangência do trabalho de Auditoria e a forma pelo qual o trabalho foi direcionado.

3o Parágrafo: determina a opinião do auditor sobre o trabalho realizado.

No entanto, pode ocorrer a inclusão de um ou mais parágrafos, em que o auditor realiza seus comentários ou referências a notas explicativas de possíveis divergências ou discordâncias em relação às demonstrações financeiras ou ao trabalho realizado. Attie (1998), com base na resolução CFC no 700, de 244-1991, classifica o parecer de auditoria, segundo a natureza da opinião em: parecer sem ressalva; parecer com ressalva; parecer adverso; e, parecer com abstenção de opinião.

O parecer sem ressalva é emitido quando as demonstrações financeiras da empresa, examinadas pelo auditor, representam adequadamente a posição patrimonial e financeira e o resultado das operações de acordo com os princípios fundamentais da contabilidade. Esse tipo de parecer indica que o auditor está convencido de que as demonstrações financeiras foram elaboradas, consoante a Normas Brasileira de Contabilidade e a legislação específica, em todos os seus aspectos relevantes (ATTIE, 1998).

Por outro lado, o parecer com ressalva indica que um ou mais valor, nas demonstrações financeiras, não refletem adequadamente a posição correta, de acordo com os princípios fundamentais da contabilidade, ou quando o auditor não consegue obter evidências adequadas que permitam a comprovação desses valores (HOOG et al., 2007).

Em Attie (1998), encontra-se que o parecer adverso é emitido quando o auditor verificar efeitos e condições, que, em sua opinião, comprometem substancialmente as demonstrações financeiras examinadas, a ponto de não ser suficiente a simples ressalva no parecer. Porém, quando o auditor não conseguir obter comprovação suficiente para fundamentar sua opinião sobre as demonstrações financeiras tomadas em conjunto, ele deve declarar que está impossibilitado de expressar suas opiniões sobre essas, o que, nesse caso, caracteriza o parecer com abstenção de opinião. 
Ressalta-se que a função da Auditoria deve ser exercida em caráter de entendimento e que o trabalho executado tenha e mereça toda a credibilidade possível, não sendo permitido existir qualquer sombra de dúvida quanto à honestidade e aos padrões morais do auditor. A profissão de Auditoria exige, assim, a obediência aos princípios éticos profissionais que, fundamentalmente, apoiam-se em: independência, integridade, eficiência e confidencialidade (ATTIE, 1998).

Além disso, todo trabalho de Auditoria repousa no estabelecimento de critérios e de metodologia que Ihe deem razoável segurança sobre a totalidade das demonstrações financeiras examinadas. $\mathrm{O}$ auditor não deve esquecer que poderá responder, civil e criminalmente, por prejuízos causados a terceiros em virtude de culpa ou dolo no exercício de suas funções. É, portanto, seu dever emitir um parecer circunstanciado que contenha as observações a respeito das deficiências e irregularidades detectadas no decorrer de suas atividades.

\section{Caracterização das Empresas}

As empresas tornam-se gêneros do tipo empresária e simples, nos termos do art. 982 do Código Civil (CC/2002), conforme distinção abaixo. A essência das diferenças, entre um objeto e outro tipo societário, revela-se no quadro 01.

Sociedade Simples: sociedade de direito privado, constituída por contrato escrito e registrado no registro civil, que não desenvolve atividades próprias de empresário. Ou seja, relação entre pessoas para explorar atividade econômica organizada, que tem por objeto o labor tecnológico nas áreas: científica, literária, cultural, artística ou profissão intelectual, sem constituir para este objeto, elemento de empresa. E tem por objetivo o lucro (HOOG, 2007).

Sociedade Empresária: é um acordo de vontades que cria uma entidade, pessoa jurídica, com fins econômicos, organizada, de direito privado, constituída por contrato escrito que se vincula ao registro Público de empresas mercantis, a cargo das Juntas Comerciais, nos termos do art. 1.150 do CC/2002; que tem por objeto o exercício da atividade própria de empresário, nos termos do art. 982, constituída sob os tipos regulados no novo Código Civil, arts. 1.039 a 1.092. Ex: qualquer tipo de sociedade que pratique a produção ou circulação de bens e serviços, como os supermercados, bancos, as indústrias em geral. Incluem-se nessa categoria todas as sociedades anônimas, independentemente do tipo de empresa (HOOG, 2003).

Quadro 01: Tipos de Sociedades.

\begin{tabular}{|c|c|}
\hline \multicolumn{2}{|c|}{ DISTINÇÃO CIENTÍFICA CONTÁBIL } \\
\hline Sociedades Empresárias & Sociedades Simples \\
\hline $\begin{array}{l}\text { Possuem denominação ou Firma. Os seus tipos possíveis são: } \\
\text { 1. Sociedade Anônima } \\
\text { - Unipessoal originária, subsidiária integral; } \\
\text { - De garantia subsidiária; } \\
\text { - S/A tradicional, mínimo de dois sócios. } \\
\text { 2. Limitada - sociedade de pessoas ou de capital } \\
\text { 3. Sociedade em nome coletivo: sócios, somente pessoas } \\
\text { físicas, responsabilidade solidária ilimitada } \\
\text { 4.Sociedade em Comandita simples- sócios: pessoa física, } \\
\text { responsabilidade ilimitada; pessoa jurídica, responsabilidade } \\
\text { limitada } \\
\text { 5.Comandita por ações- diretor; responsabilidade ilimitada }\end{array}$ & $\begin{array}{l}\text { Possuem denominação e os seus tipos possíveis são: } \\
\text { 1. Sociedade Simples } \\
\text { 2.Cooperativas com ou sem capital - responsabilidade limitada } \\
\text { ou ilimitada } \\
\text { 3.Sociedade em nome coletivo - somente constituída por } \\
\text { pessoas físicas; responsabilidade solidária e ilimitada; não } \\
\text { sujeitas à execução } \\
\text { 4. Comandita Simples - sócios: pessoa física, ilimitada; e Pessoa } \\
\text { Jurídica limitada } \\
\text { 5. Limitada - sociedade de pessoas }\end{array}$ \\
\hline
\end{tabular}

Fonte: Hoog (2007). 
As sociedades que têm por objeto o fomento comercial são genuinamente empresárias, e para os procedimentos de auditoria deve apresentar os seguintes livros: Livro de registro de códigos e abreviaturas; Livro de registro de inventário; Livro Diário; Livro de Balancetes Diários e Balanços; Razão; Registro de Duplicatas; Livro de Atas da Administração; Livro de Atas e Pareces do Conselho Fiscal; Livros de Atas da Assembleia (HOOG et al., 2007). As empresas comerciais, também, possuem contas específicas a serem analisadas pela Auditoria.

\section{Auditoria em Contas Próprias das Sociedades Comerciais}

\section{Disponível}

Franco (1979) menciona que esse grupo compreende as contas representativas de valores numerários, disponíveis em caixa, de movimento nos bancos, para livre, franca e imediata utilização. É usada para designar dinheiro em caixa e em bancos, bem como valores equivalentes, como cheques em mãos e em trânsito, que representam recursos com livre movimentação para aplicação nas operações da empresa e para os quais não haja restrições ao uso imediato (IUDíCIBUS, 2003). No exame na conta do Disponível, o auditor pode adotar os seguintes procedimentos:

Rastreamento: para determinar os bancos em que a empresa possui contas bancárias.

Contagem: contam-se os valores e documentos em poder do caixa; soma-se a contagem física realizada para conferir o saldo apurado com o boletim de caixa.

Repetição: revisa o papel de trabalho de contagem atentando para os itens que lhe pareçam anormais.

O auditor tem como finalidade determinar a existência de valores, em bancos ou com terceiros; identificar se o que a empresa possui em caixa pertence-lhe efetivamente; verificar se os princípios de contabilidade foram aplicados devidamente; buscar a existência de restrições de uso ou de vinculações em garantia; detectar se a demonstrações financeiras da entidade está classificada corretamente, e as divulgações cabíveis foram expostas por notas explicativas (IUDíCIBUS, 2003).

\section{Direitos (Créditos Operacionais)}

Os direitos compreendem as contas representativas de valores a receber, decorrentes da atividade operacional, da empresa, tais como créditos a receber de clientes (por venda de mercadorias), de empresas subsidiárias (por vendas ou fornecimento de numerário), de empregados (por adiantamento de salários), de acionistas ou de terceiros que mantêm relações de negócios com a empresa, dentro de suas atividades operacionais (FRANCO, 1979). Ribeiro (2003), sintetiza essa definição ao mencionar que "são todos os valores que uma empresa tem a receber".

Para Attie (1998), os procedimentos em Direitos (Créditos Operacionais) têm por finalidade verificar a existência e representatividade contra os devedores envolvidos, e quais pertencem à entidade, observando se os princípios de contabilidade foram utilizados de maneira uniforme, assim como a existência de restrições de uso ou de vinculações em garantia ou contingências, e se a conta está corretamente classificada. Tais procedimentos podem ser feitos através de: inspeção (conferência dos ativos tangíveis das empresas); 
contagem física dos recursos tangíveis; e, confirmação, que é a determinação de que o ativo decorrente de contas a receber pertence realmente à empresa.

\section{Estoques}

Segundo ludícibus et al. (2000), são mercadorias a serem revendidas. Os estoques compreendem todas as contas representativas de mercadorias (em depósitos, em trânsito, em consignação ou processo de importação, que constituem objeto de compra e venda pela empresa (FRANCO, 1979). As principais classes de estoque compreendem (SILVA, 2004):

Matérias-primas: são aqueles itens comprados pela empresa, geralmente materiais básicos como parafusos, plásticos, ferro.

Produtos em fabricação: Consiste em todos os itens que estão sendo utilizados no processo produtivo.

Produtos acabados: consiste em itens que foram produzidos, mas não vendidos ainda.

Mercadorias: bens comprados e destinados à venda.

A Auditoria, nessa área, realiza-se por meio da contagem, que é a conferência do estoque com os inventários apresentados; pela inspeção, ou verificação do estoque; pela confirmação de estoque em poder de terceiros. Verifica-se com isso sua existência, determinando se está na empresa ou em custódia com terceiros ou em trânsito; se pertence à companhia; se foram aplicados os princípios de contabilidade geralmente aceitos; se o mesmo não fora penhorado, ou mesmo dado em garantia, e se consta nas demonstrações financeiras das empresas.

\section{Investimentos}

Extraindo da Lei n.o 6.404/76, artigo 179, Ribeiro (2003) afirma que este grupo é formado pelas participações permanentes em outras sociedades e pelos Direitos de qualquer natureza não-classificáveis no Ativo Circulante, e que não se destinam à manutenção da atividade da companhia ou da empresa. Para Franco (1979):

são os investimentos em caráter permanente tais como os em empresas coligadas e controladas, as cauções permanentes e outros que podem ser convertidos em numerário sem prejuízo do objetivo social da empresa. (FRANCO, 1979)

Neste grupo encontram-se, como subtrações, as Provisões para Perdas, cujo objetivo consiste em cobrir as perdas prováveis na realização financeira, quando comprovadas como permanentes (IUDícIBUS, 2000).

Na Auditoria desse grupo de conta, faz-se a verificação se os investimentos estão vinculados a empresas, procedimento reconhecido como inspeção; a contagem que consiste na verificação do caixa e das aplicações financeiras. Nesse caso, os objetivos a serem alcançados na aplicação desses procedimentos são: determinar a existência de investimentos em poder da companhia ou em custódia com terceiros; o que é propriedade da empresa; a utilização dos princípios da contabilidade de forma adequada; a existência de garantias para as vinculações; a contabilização, de forma adequada, das receitas ou prejuízos; a correta classificação das demonstrações financeiras (ATTIE, 1998). 


\section{Ativo Imobilizado}

São contas que representam os imóveis, as instalações, os móveis e demais equipamentos necessários ao funcionamento da empresa comercial, bem como as correções monetárias e as depreciações respectivas (FRANCO, 1979).

No Ativo Imobilizado são classificados os Direitos que tenham por objeto bens destinados à manutenção das atividades da empresa, ou exercidos com essa finalidade, inclusive os de propriedade industrial ou comercial (RIBEIRO, 2003).

Para Iudícibus et al. (2000), o Ativo Imobilizado representa as aplicações que tenham por objetivo bens destinados à manutenção da atividade operacional da empresa, tais como, o imóvel onde está sediada a organização; instalações; móveis e utensílios; veículos; máquinas e equipamentos; no caso de indústria, marcas e patentes etc.

A auditoria do Imobilizado tem as seguintes finalidades: determinar a sua existência física, a permanência em uso e se pertencem à empresa; utilização dos princípios de contabilidade de maneira uniforme; verificar se o imobilizado não contém despesas capitalizadas e, por outro lado, as despesas não contêm itens capitalizáveis; determinar os bens do imobilizado foram adequadamente depreciados e corrigidos monetariamente em bases aceitáveis; a existência de imobilizado penhorado, dado em garantia ou com restrição de uso, e se está corretamente classificado nas demonstrações financeiras (ATTIE, 1998).

Em tal procedimento de Auditoria, utiliza-se o exame físico para realizar a inspeção dos bens do imobilizado, bem como das obras em andamento, fazendo-se a confirmação, em cartórios, das escrituras, com fornecedores quanto a bens adquiridos a prazo e, com advogados, sobre processos em andamento. Procede-se a cálculos sobre depreciação do exercício, soma das fichas individuais dos bens do imobilizados e cálculo do lucro ou prejuízo da venda de imobilizado, de acordo com Attie (1998).

A investigação, que é o exame minucioso de documentação de compras, vendas, aprovações, autorizações e contas de manutenção e reparos, também auxilia nesse processo. $O$ auditor pode complementar seu trabalho com o inquérito acerca da variação do saldo do imobilizado; sobre a existência de obsoletos e tendência de expansão ou remodelação da empresa. Necessária se faz, ainda, a observação sobra a classificação das contas, segundo os princípios da contabilidade (FRANCO et al., 2001).

De maneira abrangente, para as empresas comerciais, por suas peculiaridades, existem procedimentos específicos a serem utilizados na Auditoria, os quais, na concepção de Attie (1998), devem ser: inspeção, contagem, confirmação e repetição. Com isso, o autor identifica que a determinação dos procedimentos de Auditoria, em cada um dos casos, deve ser feita de tal sorte que se obtenham resultados satisfatórios, de acordo com cada uma das circunstâncias observadas nas referidas empresas.

\section{CONCLUSÕES}

No percurso do presente trabalho monográfico verifica-se que grandes transformações políticoeconômicas ocorreram em todo o mundo, trazendo impactos diretos para as organizações, no sentido de 
procurar dispor de informações contábeis seguras e fidedignas que lhes assegure a tomada de decisão mais adequada aos seus objetivos, além de garantir a confiança e transparência nas transações. Para tanto, a Auditoria vem sendo utilizada de maneira a fornecer as informações indispensáveis à redução de riscos, alocação apropriada de recursos, preservação do patrimônio, dentre outras, visando à melhoria contínua diante da crescente complexidade da administração dos negócios e das práticas financeiras.

A Auditoria, certamente, não propicia a solução para todos os problemas existentes nas empresas, contudo, por meio de seus trabalhos de análise e interpretação das informações contidas nas demonstrações contábeis fornece uma base sólida para que a alta administração tome decisões pautadas em procedimentos de comprovação, além de permitir que conduza melhor a organização no alcance dos objetivos pretendidos, resguardando interesses não somente de administradores, investidores, acionistas, fornecedores etc., mas da sociedade em geral.

Pela literatura analisada, detectou-se que a Auditoria tem se adaptado às necessidades modernas através de regras implantadas para cercear as possibilidades de riscos e erros, com sistemas de informações integrados e estratégicos que contribuem para tornar o desempenho empresarial cada vez mais eficiente e, ainda, o trabalho das organizações mais competentes, fortalecendo os controles contábeis e operacionais de maneira a antecipar o conhecimento dos problemas existentes para que suas causas sejam controladas em tempo hábil, evitando as consequências dos efeitos que lhes possam ser prejudiciais.

A partir da pesquisa que embasa o presente estudo, pode-se observar que nas empresas comerciais, a Auditoria utiliza-se de um conjunto de técnicas e procedimentos para levantamento dos dados que englobam os diferentes segmentos da organização. A verificação do que é mais adequado a essas empresas considerou, também, que para cada grupo de conta analisada, existem orientações diferenciadas para utilização de tais procedimentos, de acordo com as finalidades pré-determinadas pela Auditoria.

Nesse contexto, percebe-se que a Auditoria Contábil orienta as empresas comerciais a praticarem a eficácia dos controles, integridade e confiabilidade das informações e registros, levando em conta as políticas, metas, planos, procedimentos, leis, normas e regulamentos que tratam dos preceitos técnicos emanados da doutrina contábil e seus órgãos reguladores. Dessa forma, permite oferecer ao mercado uma empresa sólida e com poder efetivo para competir em um mundo altamente globalizado.

Conclui-se que a Auditoria, vista como profissão, tem experimentado expressiva evolução nos últimos anos, desenvolvendo-se com diferentes graus de especialização, admitindo deste modo, aos que militam na área, possibilidades de acréscimo substancial de conhecimentos em todos os campos que abrangem, direta ou indiretamente, a Contabilidade.

Finalmente, acredita-se que o presente trabalho atendeu aos objetivos propostos, fornecendo uma visão integrada do trabalho de Auditoria, especificamente em empresas comerciais, foco desta pesquisa, apresentando elementos suficientes para o conhecimento prévio do desempenho operacional na referida atividade, no que se refere às estratégias metodológicas a serem utilizadas no processo auditorial. 


\section{REFERÊNCIAS}

ALMEIDA, M. C.. Auditoria: um curso moderno e completo. 6 ed. São Paulo: Atlas, 2003.

ATTIE, W.. Auditoria: Conceitos e Aplicações. 3 ed. São Paulo: Atlas, 1998.

BOYNTON, W. C.; JOHNSON, R. N.; KELL, W. G.. Auditoria. 7 ed. São Paulo: Atlas, 2002.

CFC. Conselho Federal de Contabilidade. Princípios fundamentais e normas de contabilidade: auditoria e perícia. Brasília: CFC, 2003.

CORREIA, A. C.. Um pouco da história da Auditoria Interna. 2002.

CREPALDI, S. A.. Contabilidade - Auditoria: origem, evolução e desenvolvimento da auditoria. Revista Contábil \& Empresarial, 2010.

FRANCO, H.. Contabilidade Comercial. 12 ed. São Paulo: Atlas, 1979

FRANCO, H.; MARRA, E.. Auditoria Contábil: normas de auditoria: procedimentos e papéis de trabalho: programas de auditoria: relatórios de auditoria. 4 ed. São Paulo: Atlas, 2001.

HENDRIKSEN, E.. Teoria da contabilidade. São Paulo: Atlas, 1999.

HOOG, W. A. Z.. Prova pericial contábil: aspectos práticos \& fundamentais. 5 ed. Curitiba: Juruá, 2007.
HOOG, W. A. Z. Novo código especial para contadores. Curitiba: Juruá, 2003.

HOOG, W. A. Z.; CARLIN, E. L. B.. Manual de auditoria contábil das sociedades empresárias. 2 ed. Curitiba: Juruá, 2007.

IBRACON. Instituto Brasileiro de Contabilidade. Norma de Procedimento de Auditoria. São Paulo: IBRACON, 2018.

IUDÍBUS, S. A.. Teoria da Contabilidade. 5 ed. São Paulo: Atlas, 2004

IUDÍBUS, S. A.; MARION, J. C.. Contabilidade Comercial. 4 ed. São Paulo: Atlas, 2000.

IUDÍBUS, S. A.; MARTINS, E.; GELBCKE, E. R.. Manual da Contabilidade: das sociedades por ações. 6 ed. São Paulo: Atlas, 2003.

LUNA, S. V.. Planejamento de pesquisa: uma introdução. São Paulo: Atlas, 2000.

OLIVEIRA, S. L.. Tratado de metodologia científica: projetos de pesquisas, TGI, TCC, monografias, dissertações e teses. São Paulo: Pioneira, 2002.

RIBEIRO, O. M.. Contabilidade comercial fácil. 15 ed. São Paulo: Saraiva, 2003.

SILVA, V. P. C.. Auditoria Interna: a importância da Auditoria Interna nos processos de gestão de estoques em empresas do setor atacadista. Artigo Científico (Bacharelado em Ciências Contábeis) - Universidade Estadual de Brasília, Brasília, 2004.

A CBPC - Companhia Brasileira de Produção Científica (CNPJ: 11.221.422/0001-03) detém os direitos materiais desta publicação. Os direitos referem-se à publicação do trabalho em qualquer parte do mundo, incluindo os direitos às renovações, expansões e disseminações da contribuição, bem como outros direitos subsidiários. Todos os trabalhos publicados eletronicamente poderão posteriormente ser publicados em coletâneas impressas sob coordenação da Sustenere Publishing, da Companhia Brasileira de Produção Científica e seus parceiros autorizados. Os (as) autores (as) preservam os direitos autorais, mas não têm permissão para a publicação da contribuição em outro meio, impresso ou digital, em português ou em tradução. 